HUDON, François, avec la collaboration de Karine FORTIN et Alex HARPER, L'histoire du Club Saint-James de Montréal, 1857-1999/History of the Saint-James's Club of Montreal (Montréal, Clulb Saint-James de Montréal, 2000), 112 p.

\title{
Paul-André Linteau
}

Volume 55, numéro 2, automne 2001

URI : https://id.erudit.org/iderudit/010392ar

DOI : https://doi.org/10.7202/010392ar

Aller au sommaire du numéro

Éditeur(s)

Institut d'histoire de l'Amérique française

ISSN

0035-2357 (imprimé)

1492-1383 (numérique)

Découvrir la revue

Citer ce compte rendu

Linteau, P.-A. (2001). Compte rendu de [HUDON, François, avec la collaboration de Karine FORTIN et Alex HARPER, L'histoire du Club Saint-James de Montréal, 1857-1999/History of the Saint-James's Club of Montreal (Montréal, Club

Saint-James de Montréal, 2000), 112 p.] Revue d'histoire de l'Amérique française, 55(2), 313-314. https://doi.org/10.7202/010392ar d'utilisation que vous pouvez consulter en ligne. 
adultes. L'histoire de la prise en charge de l'enfance par l'État est d'abord largement axée sur le désir des autorités d'atteindre ces franges de population qui échappent à son emprise.

Le régime actuel de protection de la jeunesse est décrit minutieusement dans la seconde partie de l'ouvrage. On retrouve ici toute l'expertise de la juge qui illustre la mise en action de la loi et nous aide à en saisir les subtilités. L'ouvrage est d'un apport précieux pour ceux qui désirent comprendre pourquoi le modèle québécois de la protection de la jeunesse mérite d'être défendu.

SYLVIE MÉNARD

Département d'histoire Université du Québec à Montréal

HUDON, François, avec la collaboration de Karine FORTIN et Alex HARPER, L'histoire du Club Saint-James de Montréal, 1857-1999/History of the Saint-James's Club of Montreal (Montréal, Club Saint-James de Montréal, 2000), I 12 p.

Fondé en 1857, le Saint-James's Club (le nom bilingue ne viendra qu'en 1981) a longtemps été un symbole de l'establishment anglo-montréalais. Lors de son $140^{\mathrm{e}}$ anniversaire, ses dirigeants ont eu l'idée d'en faire rédiger l'histoire. L'ouvrage se présente comme un album illustré, imprimé sur papier glacé. Le français occupe les pages de gauche, l'anglais, celles de droite. Le texte est structuré autour de trois chapitres principaux intitulés, sans grande originalité, "Le premier clubhouse», "Le deuxième clubhouse» et "Le troisième clubhouse». On y trouve aussi plusieurs encadrés livrant soit la biographie d'un des membres importants, soit le récit d'un aspect particulier de l'histoire du Club.

L'auteur a voulu situer l'établissement dans son époque en nous présentant, de temps à autre, un portrait des transformations sociales et spatiales de Montréal. L'intention est louable, mais l'arrimage de ces deux échelles historiques n'est pas parfaitement réussi. Si le caractère élitiste du membership est bien souligné, il n'y a pas d'analyse fine de l'évolution de sa composition socio-économique (part respective des marchands, des industriels, des membres des professions libérales), ni de sa composition ethnique (poids respectif des Anglais, des Écossais, des Irlandais). La faible représentation des Canadiens français pendant plus d'un siècle, puis leur ascension rapide par la suite (ils sont aujourd'hui majoritaires) sont bien exposées. C'est aussi le cas pour l'ouverture à la présence des femmes, un processus lent et longtemps ségrégationniste. 
L'auteur offre une bonne description de l'agencement intérieur des immeubles occupés par le Club et quelques aperçus du fonctionnement de l'établissement. Quoique utile, cet ouvrage commémoratif laissera le lecteur sur sa faim. Il est ça et là entaché de coquilles et de fautes.

PAUL-ANDRÉ LINTEAU Département d'histoire Université du Québec à Montréal

PRÉVOST, Robert, Trois siècles de tourisme au Québec (Sillery, Septentrion, 2000), 365 p.

Robert Prévost avertit le lecteur dans son introduction qu'il n'a pas écrit ici « une histoire du tourisme au Québec » couvrant trois siècles mais bien "une chronique évoquant les principales étapes qui l’ont marquée», car «il ne se penche pas sur l'importance socio-économique du phénomène » (p. 7). Il qualifie d'ailleurs ce texte de «document» et espère qu'il saura "être utile à quiconque souhaitera $[. .$.$] un jour analyser en profondeur" le$ tourisme au Québec (p. 9). Cette évaluation résume bien la nature et la contribution de cet ouvrage. Il serait possible de la peaufiner encore davantage pour dire que ce «document» constitue en grande partie le témoignage d'un acteur principal ayant travaillé dans le secteur du tourisme au Québec. Robert Prévost fut, en effet, fonctionnaire pendant 32 ans, occupant une diversité de postes de haut-grade dans plusieurs organismes de la fonction publique provinciale destinés a la promotion du tourisme au Québec. Bien qu'il ne fasse pas mention de sa propre expérience, il n'en demeure pas moins que près des deux tiers de son ouvrage, découpé en 97 courts chapitres de 2 à 6 pages, sont consacrés aux années durant lesquelles l'auteur loge à l'enseigne du tourisme à la fonction publique. Il cherche essentiellement à mettre en relief les diverses étapes qui ont amené le gouvernement provincial à s'engager de plus en plus directement dans la promotion touristique du Québec au sortir de la Deuxième Guerre mondiale et tout particulièrement durant les deux premières décennies de la Révolution tranquille. L'année 1960 est, à son avis, une date charnière : c'est alors que les élus prennent les initiatives qui s'imposent pour permettre au Québec de faire ses preuves dans le secteur du tourisme. En fournissant un recensement des initiatives gouvernementales, l'auteur crée un cadre préliminaire qui sera d'une grande utilité pour ceux et celles qui veulent produire des analyses plus fouillées et soutenues par des interprétations ancrées dans les divers contextes socio-économiques et 